\title{
Criminology Open
}

\section{Why and How Criminology Should Be Free}

\section{Scott Jacques}

Published on: May 10, 2020

DOI: $10.21428 / \mathrm{b} 7013076 . \mathrm{b} 4827714$

License: Creative Commons Attribution 4.0 International License (CC-BY 4.0). 


\section{Fellow Criminologists:}

We can make our written works free to everyone, with only a little extra effort. Too much of what we write is behind publisher paywalls. The current system is socially unjust and irrational. It hampers the spread of scholarship's benefits, costing more than it should, limiting our impact. 1 It is easy to blame the publishers or ignore the problem. But today, we have the power - and thus the moral responsibility - to make our works Open Access (OA). This letter is a call to action: From now on, we must make our works freely available to everyone. $\underline{2}$ Below, I explain how.

\section{Broken Promise}

First, though, I should confess that I am breaking a promise: to create an OA criminology journal, which I titled Criminology Open. $\underline{3}$ While trying to develop it, I learned a lot about journal publishing, OA, and open science more broadly. 4 Ironically, the biggest lesson is we do not need OA journals to make our works OA. Already, we are able to share the vast majority of our works in a legal, free, public manner over the internet. The major problem, then, is not publishers, copyright or technology. It is us.

\section{Key Concepts}

For readers new to OA, it is important to list and define a few key concepts. $\underline{5}$ In a work's "life-course," it transitions from being a complete draft (called a "preprint") to accepted for publication ("postprint") to finalized for publication ("publisher version"). Those stages correspond with color-coded types of OA. In this letter, two are most important: "green access" - the sharing of postprints (or preprints); and, "gold access" - the sharing of publisher versions.

\section{Why Isn't Criminology Open?}

Compared to our peers in many other fields, criminologists know less about OA and engage in less of it. I assume the former causes the latter; hence this letter. Yet there are other inhibitors. $\underline{6}$ Most of us cannot afford to pay the substantial "processing charge" to publish our works as gold access. $\underline{7}$ There are OA outlets without those fees, $\underline{8}$ called "diamond access," but they are not "top" $\underline{9}$ outlets in criminology. We could, nevertheless, prioritize OA by publishing in them. But personal rewards - promotion, tenure, money, and so on - are more important to many of us, so we opt to get our works published in paywalled outlets (that we deem) closer to the top. 


\section{Why Criminology Should Be Open}

There is a compromise, however. To make your works OA, you do not have to pay expensive fees or change where you publish. We can and should take advantage of green access. This is already allowed by the vast majority of criminology journals, for example. By going green, we will free our works from paywalls, making the system more socially just and rational by facilitating the free sharing of scholarship, thereby

increasing its benefits, lowering its costs, and increasing our impact. $\underline{10}$ Your works will gain usage, downloads, $\underline{11}$ and citations, especially among people - in and outside academia - who do not already enjoy privileged access. Better still, providing green access is not difficult or time consuming; more about this, below.

\section{What We Should Do}

I think green access is the best way to make criminology more open because it is cheap and requires little systemic change. That said, prescriptions for how to pursue OA should cover the full range of options - green, gold and diamond access - for articles, chapters, and books, conceivably more. $\underline{12}$ With that in mind, below is what I think every criminologist should do.

- Make OA an important part of deciding where we publish. When considering potential outlets, know if each is diamond access, provides gold access, or permits green access. $\underline{13}$ There are other considerations, but leaving those constant: Prioritize publishing in outlets that are, one, more accessible and, two, less expensive to publish in. That makes diamond access outlets the best, but, if none is right for a given work, submit to those that permit immediate green access or, if you can afford it, provide gold access. Among the OA options, the least good is embargoed green access; this should be the last resort. $\underline{14}$ Forgo all other outlets.

- When a work is accepted for publication, take advantage of the ability to make it OA. Get the publisher version (if diamond or gold access) or postprint (if green access) uploaded to the websites of your choice. One should be your institution's repository, and another should be more personal (e.g., CrimRxiv) but to everyone's benefit. $\underline{15}$ Don't be shy about asking your librarian for help.

This letter is the first in a series on how we can be better stewards of criminological information, knowledge, and understanding. In the meantime, if you would like to share your thoughts or learn more, please comment below or email me. I hope you will. 
For a more open future,

Scott Jacques, Associate Professor of Criminal Justice and Criminology, Andrew Young School of Policy Studies, Georgia State University

(ScottJacques@CriminologyOpen.com)

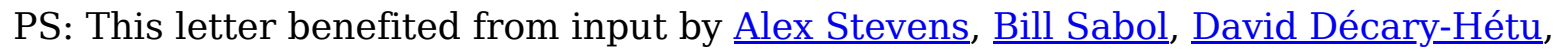

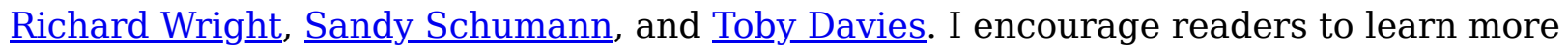
about PubPub, a member of MIT's Knowledge Futures Group, which I used to write and publish this letter.

\section{Footnotes}

1. For an example of how paywalls harm criminology's impact, see Ashby's "Three Quarters of New Criminological Knowledge is Hidden from Policy_ Makers". Another problem with the current system is it causes crime by motivating people to use illegal pirate websites, such as Sci-Hub. $\subseteq$ 2. Suber defines open access as "literature [that] is digital, online, free of charge, and free of most copyright and licensing restrictions" (ㅁpen Access, MIT Press). For more information about open access, I recommend that book and Willinsky's The Access Principle, which are free to download. Another useful resources is the Harvard Open Access Project. $\leftrightarrows$

3. 
I promised to create Criminology Open in a tweet, dated August 22, 2018: "I recently started developing @ㄷiminologyㅡ to provide criminologists with 1) an open access journal that's ... 2) high quality, from review to production to dissemination[;] 3) free to everyone[;] 4) with running costs incurred by a supporting institution and me."

I made headway in setting up its editorial board; created a Criminology Open logo (the open access symbol turned 45 degrees counter-clockwise) and chose a correspondence font (Century Gothic); submitted a funding request to Arnold

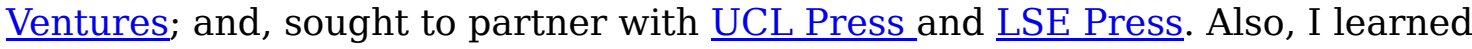
about website development and design; cloud vs. dedicated servers; publishing platforms (e.g., ㅁpen Journal Systems, PubPub, $\underline{\text { Scholastica, }}$ ScienceOpen); typesetting and copyediting; indexing, archiving, ㅇIs, ISBNs, and $\underline{\text { ORCiDs. }}$

I want to thank by name the people who agreed to serve on the editorial board, and apologize for wasting their time with an unfulfilled promise: Andrea Allen; Martin Bouchard; Toby_Davies; David Decary-Hetu; Barbora Hola; Marie Lindegaard; Kim Møller; Sveinung Sandberg; and, Stephanie Wiley

4. For more information on open science, I recommend the websites of SPARC, The Center for Open Science, and this Wikipedia article.

5. For brevity, there are many nuances that I will omit. $\subseteq$

6. Without major change by governments, funders, universities, publishers, and their various outlets, there is less likely to be a substantial increase in OA to criminology works. Fortunately, however, such changes are being made, with more on the horizon. Academic and funding institutions are adopting policies that make OA the norm. For more information, see, for example, DORA, Plan S, and the policies and adopters listed on the Harvard Open Access Project. $\subseteq$ 7. For example, the fee to publish in The British Journal of Criminology is $\$ 4,350$ and in Criminology is $\$ 3,300$. These are normal costs for "hybrid journals," i.e. those that publish articles as paywalled and OA. Probably the best "all OA journal" is Crime Science, with a fee of $\$ 1290$. Outlets do sometimes waive the fee. I am thankful that UCL Press did so for my book Grey Area. 8. To my knowledge, the diamond access journals in criminology are the following. If one is not such or you know of another, please add a "Comment". British Journal of Community Justice; Criminological Encounters; The 
Criminology, Victimology, and Security Journal; The International Journal for Crime,.Justice and Social Democracy; The International Journal of Cyber Criminology; The International Journal of Criminal Justice Sciences; The Journal of Criminal Law and Criminology; Journal of Illicit Economies and Development; and, The Journal of Qualitative Criminal Justice and Criminology..

9. For information on the problems with journal rank as a metric for evaluating the quality of articles and authors, see https://sfdora.orgL. Criminologists lag behind in this movement, too. $\_$

10. See, for example, Hitchcock's bibliography, "The Effect of Open Access and Downloads ('Hits') on Citation Impact”..

11. Downloads is a proxy for reads. $\_$

12. My sense is that $\mathrm{OA}$ is most common for articles, less for chapters, and least of all for books. Also, gold access is more available than green access, which is more available than diamond access. $\_$

13. You can get the answers by consulting your librarian or the websites of each outlet, their respective publishers, or SHERPA/RoMEO.. \pm

14. For journals that have an embargo, you have at least a few options. If your institution or funder has a rights-retention policy, you are free to share your postprint right away, regardless of a publisher's embargo (should there be one); for details, see chapter 4, "Policies", of Suber's Open Access (MIT Press). If not, make an "appointment" in your calendar for the embargo's end date, and upload the paper to that appointment. When the day comes, your former-self will notify you to upload the paper. Also, some repositories allow you to specify the embargo period and will automatically make the work public when it ends. $\subseteq$

15. By uploading papers in your institution's repository, you show administrators that open access is important and signal that they should further support it. The advantage of uploading to websites like OSF or ResearchGate is that if you leave your current institution, they go with you. $\_$ 